\title{
Pengembangan Kewirausahaan di Universitas Muhammadiyah Pontianak
}

\author{
Entrepreneurship Development in Universitas Muhammadiyah Pontianak
}

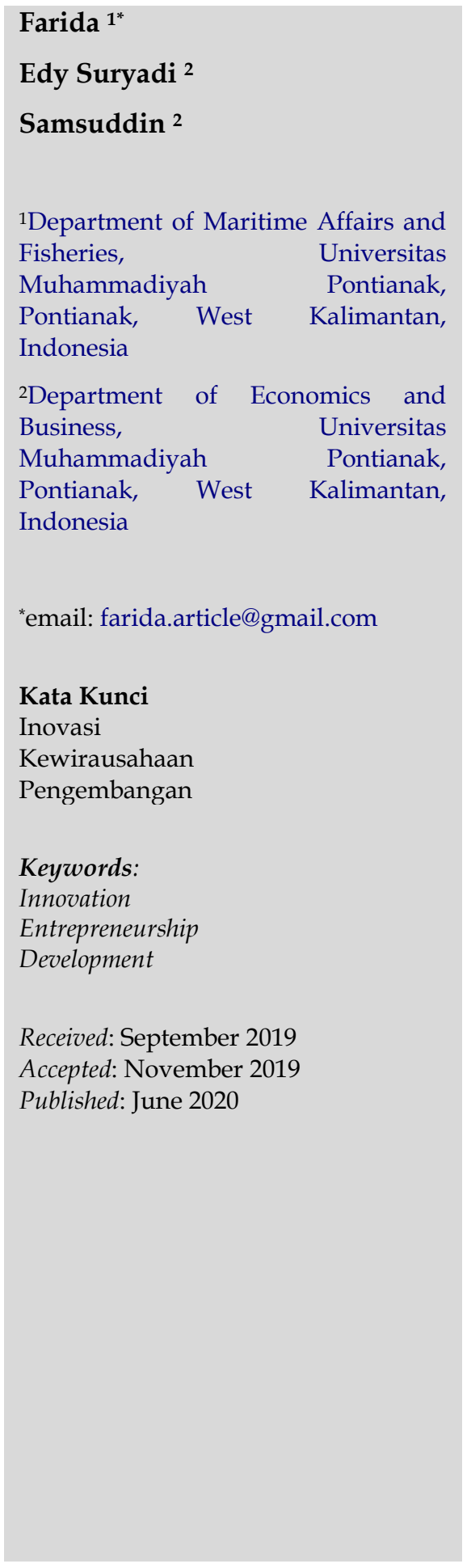

\begin{abstract}
Abstrak
Program Pengembangan Kewirausahaan (PPK) di Universitas Muhammadiyah Pontianak (UM Pontianak) merupakan program dengan misi menghasilkan wirausaha baru, melalui program yang terintegrasi dengan melibatkan para mahasiswa pengelola PPK serta Narasumber. Kegiatan-kegiatan PPK UM Pontianak antara lain pelatihan manajemen, skills usaha dengan Metode Start and Improve Your Businees yang terdiri dari modul Generate Business Idea, Start Your Business, dan Improve Your Business, meliputi Pemasaran, Perencanaan Keuangan, Pembukuan, Pembelian, Kontrol Stok dan Pembiayaan, dalam konteks pemberdayaan potensi entrepreneurship bagi mahasiswa. Peserta membentuk dan meningkatkan keterampilan dalam menghasilkan produk di workshop dan laboratorium program studi. Pelatihan skills dan manajemen dilaksanakan untuk memberikan pengetahuan kewirausahaan, mendorong tumbuhnya motivasi berwirausaha, meningkatkan pemahaman manajemen, serta membuat rencana pengembangan usaha. Mahasiswa yang telah mulai berwirausaha, mahasiswa Program Kreatifitas Mahasiswa Kewirausahaan, alumni yang berminat atau baru merintis usaha bisa menyempurnakan kegiatan kewirausahaan yang telah dilakukan sebelumnya. Pengelola PPK UM Pontianak menggali jenis komoditas bisnis para tenant sesuai dengan bakat dan minatnya. Unit layanan program PPK UM Pontianak setiap tahun akan menghasilkan minimal lima wirausaha baru mandiri berbasis iptek per tahun yang siap beraktivitas di masyarakat.
\end{abstract}

\begin{abstract}
The Entrepreneurship Development Program (PPK) at Universitas Muhammadiyah Pontianak (UM Pontianak) is a program with the mission of producing new entrepreneurs, through an integrated program involving the students managing PPK and resource persons. PPK UM Pontianak activities include management training, business skills with the Start and Improve Your Business Method which consists of Generate Business Ideas, Start Your Business, and Improve Your Business modules, including Marketing, Financial Planning, Bookkeeping, Purchasing, Stock Control, and Funding, in the context of empowering the potential of entrepreneurship for students. Participants form and enhance skills in producing products in workshops and laboratory study programs. Skills and management training is carried out to provide entrepreneurial knowledge, encourage entrepreneurship motivation, improve management understanding, and make business development plans. Students who have started entrepreneurship, Entrepreneurship Student Creativity Program students, alumni who are interested in or are just starting a business can perfect their previous entrepreneurial activities. Manager of PPK UM Pontianak explores the types of tenant business commodities according to their talents and interests. The PPK UM Pontianak program service unit will produce at least five new science and technology independent entrepreneurs per year who are ready to do activities in the community.
\end{abstract}




\section{PENDAHULUAN}

Kaum muda di Indonesia seperti halnya kaum muda di seluruh dunia, menghadapi tantangan- tantangan sosial dan ekonomi. Tantangan utama antara lain mencakup pengangguran dan pengangguran terselubung (Wardhana et al., 2019). Sejak tahun 1980-an, angka pengangguran kaum muda telah mengalami peningkatan mencapai $\pm 25 \%$ di daerah perkotaan dan $\pm 15 \%$ di daerah pedesaan. Selama sepuluh tahun terakhir, angka pengangguran ini terus meningkat dan peningkatan terbesar berasal dari kaum perempuan dan lulusan perguruan tinggi atau Universitas (Probosiwi, 2016).

Jumlah pengangguran tersembunyi atau pekerja yang kurang terampil angkanya juga tinggi, terutama di kalangan kaum muda yang terbatas pendidikannya (Hartina, 2009). Umumnya, kaum muda yang memiliki latar belakang pendidikan terbatas ini bekerja di bisnis keluarga yang terdiri dari $\pm 60 \%$ dari pengangguran terselubung di Indonesia (Dongoran et al., 2016). Pengangguran terselubung di kalangan kaum muda dan penduduk Indonesia pada umumnya akan membatasi kemampuan industri negara ini untuk memperoleh manfaat dari inovasi dan keterampilan yang melekat pada angkatan kerja yang hilang (Hafni \& Rozali, 2015). Penciptaan lapangan kerja melalui upaya penciptaan wirausaha atau entrepreneneurs merupakan strategi kunci dalam menyelesaikan masalah pengangguran dan pengangguran terselubung yang tengah dihadapi oleh negara Indonesia (Wijayanto \& Ode, 2019). Penciptaan lapangan kerja akan memberikan kontribusi yang besar terhadap perkembangan sosial ekonomi, pemberantasan kemiskinan dan pemecahan masalahmasalah sosial, eksklusivitas, keputusasaan dan frustasi (Maryam \& Indriani, 2015).

Potensi dan nilai ekonomi produk mahasiswa $\mathrm{PKMK} /$ mahasiswa/alumni yang merintis usaha baru dan yang berminat sebagai tenant, yaitu beberapa mahasiswa dan alumni Universitas Muhammadiyah Pontianak (UMP) telah merintis kegiatan usaha yang pasarnya cukup menjanjikan, seperti beberapa mahasiswa yang telah merintis usaha seperti "Sambal Hero" (Usaha Sambal Kemasan Berbahan Dasar Udang Hebi Borneo), Fido Karater Kreativitas Mahasiswa Universitas Muhammadiyah Pontianak, Nasiku "Sarapan Praktis Khas Nusantara Dalam Kemasan Modern", Es Krim Tradisional Kautsar, (Tehdapur) Teh Daun Purik/Kratom Khas Kapuas Hulu dan lain-lain. Mereka masih memerlukan pembinaan melalui program PPK untuk Mengembangkan keterampilan dan sikap kewirausahaan melalui simulasi bisnis atau menjalankan bisnis mereka sendiri, memberikan informasi yang utuh mengenai wirausaha dan dunianya sehingga membangun mental yang kokoh, dan berinteraksi dengan model dan contoh pengusaha sukses. Program Pengembangan Kewirausahaan UMP merupakan fasilitas yang dikelola oleh para dosen dan staf UMP yang menawarkan beberapa paket terpadu kepada para pengusaha atau alumni dan mahasiswa.

Program Pengembangan Kewirausahaan UMP merupakan unit organisasi yang menyediakan sarana dan prasarana serta pelayanan terpadu dalam mengembangkan wirausaha baru agar berkembang menjadi pengusaha tangguh dan mandiri (Jaharuddin et al., 2019). Dengan demikian diharapkan Program Pengembangan Kewirausahaan UMP mempunyai peran dalam mendorong laju pertumbuhan dan kemajuan ekonomi regional maupun nasional untuk mencapai masyarakat yang lebih sejahtera (Awandari \& Indrajaya, 2016).

Metode pengoperasian di Program pengembangan kewirausahaan mengikuti prinsip "learning by doing", yaitu mengajak para tenant untuk memperhatikan, mempelajari, mencoba membuat desain dan 
melakukan/menjalankan produksi, turut serta menangani pemasaran, dan melakukan evaluasi terhadap seluruh aktivitas yang telah dijalankan (Budiyanto \& Rofieq, 2016). Harapan dari penggunaan metode ini adalah agar para peserta dapat meresapi proses pembuatan desain, produksi hingga pemasaran, sehingga pada akhirnya akan mudah untuk mengadopsi hal-hal yang telah dialami di PPK untuk dibuat dan dikembangkan di lingkungan masingmasing. Jadi, peranan PPK adalah sebagai tempat pendadaran terhadap para mahasiswa dan alumni universitas agar jiwa wirausaha mereka menjadi sebuah sikap wirausaha yang mandiri (Shodikin et al., 2018). Selain dilakukan secara offline program PPK di UMP juga menerapkan sistem online seperti yang diktetahui pada tahun 1999 pemerintah Denmark berinisiatif membangun sebuah model kursusus Bagi para guru untuk meningkatkan keterampilan menggunakan piranti IT. Model Kursus ini memadukan keterampilan menggunakan keterampilan menggunakan piranti teknologi informasi dengan pedagogi. Banyak negara eropa mengikuti langkah Denmark ini hasilnya pada tahun 2010 program ini telah diangkat menjadi standar penggunaan teknologi informasi di sekolah di wilayah eropa (Andiarini et al., 2018). Maka pada penerapan PPK di UMP melakukan inovasi dengan membuat pelatihan/bimbel online dimana para peserta (pengusaha) dan calon pengusaha dapat belajar secara online tanpa adanya batasan wantu dan biaya, dengan adanya mereode tersebut dapat meciptakan lingkungan pembelajaran yang unteraktif dimana mahasiswa akan di bimbing setiap waktu dan dimanapun selama terdapat akses internet, dengan pemateri dari pihak dosen dan para praktisi membuat media pembelajran tersebut berkulaitas selain itu PPK juga membentuk komunitas pengusaha serta bisnis center secara online.

\section{METODOLOGI}

\section{Pola Rekruitmen Sebelum Pelatihan}

Pola rekrutmen tenant peserta PPK dilaksanakan secara berjenjang, yaitu: Rekrutment tenant peserta program kewirausahaan dibawah unit layanan PPK setiap tahun dilakukan dengan metode test ujian online, tahapan tersebut adalah:

1. Melakukan sosialisasi kepada ketua-ketua program studi dan mahasiswa yang mendapatkan hibah PKMK, KBMI, Ormawa serta mahasiswa danalumni yang berminat di bidang kewirausahaan, seperti ditunjukkan pada Gambar 1:

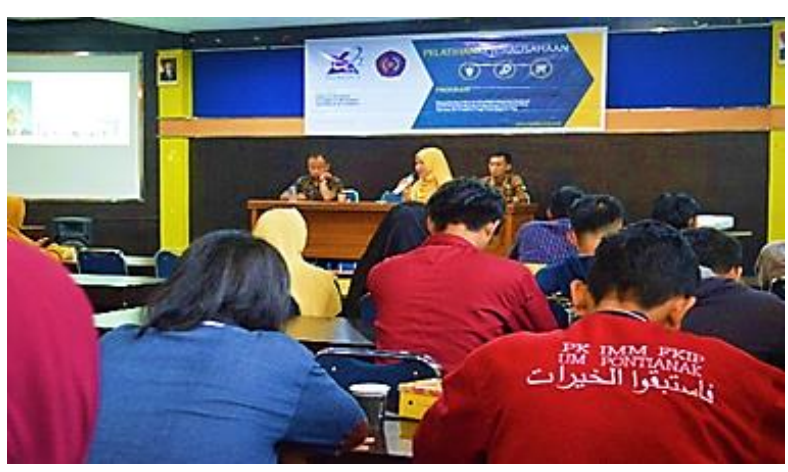

Gambar 1. Sosialisasi Program PPK

2. Melakukan seleksi (recruitment test) terhadap pendaftar program PPK di frodine.com.

3. Sejumlah (20-30) puluh mahasiswa PKMK, KBMI, Ormawa serta mahasiswa dan alumni yang sudah berhasil lolos dari recruitment test online berhak mengikuti program perkuliahan kewirausahaan (KWU) berupa pendalaman materi/workshop. Pola recruitment peserta program kewirausahaan PPK UMP, seperti ditunjukkan pada Gambar 2 berikut: 


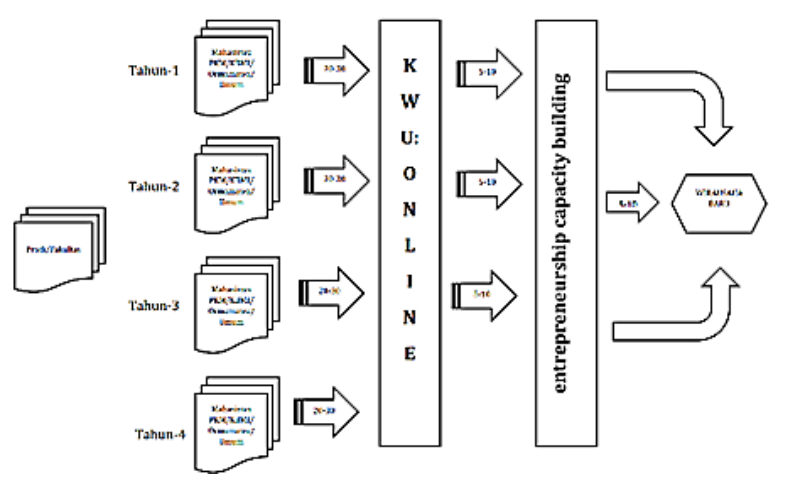

Gambar 2. Pola rekrutmen peserta program kewirausahaan PPK

Metode Pendekatan pola pemberian bantuan teknologi dan metode penyelesaian masalah

Metode pendekatan PPK dalam konteks pemberdayaan potensi entrepreneurship mahasiswa mahasiswa menggunakan metode PALS (Participatory Action Learning System). Metode pendekatan PPK dengan metode PALS secara digramatik ditunjukkan pada Gambar 3 berikut:

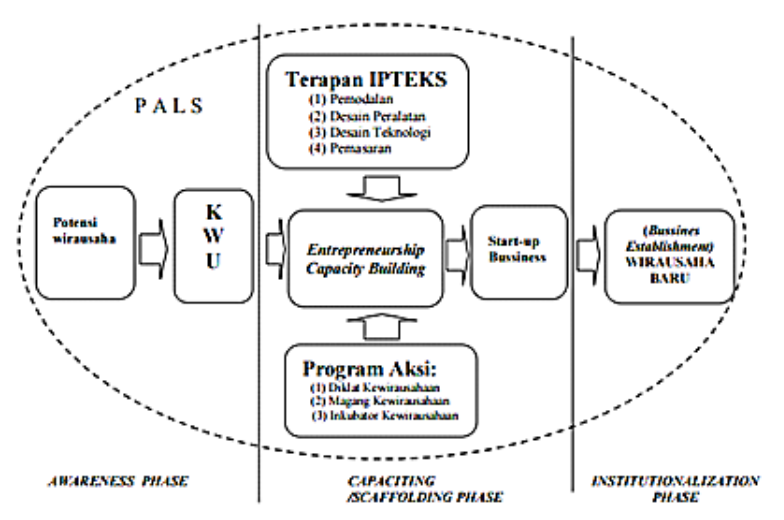

Gambar 3. Metode Participatory Action Learning Systems

\section{Fase Penyadaran Kewirausahaan}

Fase ini bertujuan membentuk dan mengembangkan sikap dan perilaku 'entrepreneur', yang mampu berkreasi, menciptakan inovasi, dan proaktif dalam menghadapi perkembangan lingkungan. Bentuk teknis pelatihan yang diterapkan adalah classical, studi kasus, diskusi, dan simulasi yang dilakukan secara offline melalui pelatihan dengan mengadopis ILO dan online pada website www.frodine.com.
Selain itu proses pelatihan selanjutnya adalah melakukan inkubator bisnis terhadap peserta yang telah mengikuti pelatihan dan mengikuti kegiatan workshop. Inkubator ini bertujuan melatih diri untuk mengaplikasikan keterampilan di tempat di dunia nyata, mengetahui dan menyesuiakan keterampilan yang dimiliki dengan kondisi nyata dalam praktik, sehingga dapat diketahui kendala/kesulitan yang ditemukan dalam praktik. Pada prinsipnya inkubator bisnis PPK merupakan bentuk bekerja dan belajar. Bentuk teknis dari inkubator bisnis yang diterapkan adalah melakukan penerapan belajar dengan sistem dropship yang memungkinkan peserta untuk dapat belajar bagaimana menjadi seorang wirausaha karena dengan sistem dropship mereka akan belajar bagaimana melakukan riset pasar, manajemen produk, melayani konsumen, peserta dapat belajar memanajemen untuk dan rugi. Kegiatan dropship dilakukan di marketplace.

2. Fase Pengkapasitasan dan Pendampingan.

Fase ini bertujuan membantu dan membimbing proses menyusun manajemen dan produksi, memecahkan masalah-masalah yang dihadapi oleh para tenant sehubungan dengan usaha/bisnis-nya. Sifat bantuannya adalah konsultasi yang dilakukan secara berkesinambungan dengan memegang prinsip manajemen kewirausahaan. Lembaga yang menjadi mitra dalam pembinaan dan pembimbingan usaha antara lain: Dekaranasda Kota Pontianak, Dinas Kesehatan, Dinas Koperasi dan UKM. Proses pembimbingan juga dilakukan dilakukan melalui online melalui website www.officialppkump.org.

Pembimbingan Pasar juga merupakan salah satu fase pendampingan, bertujuan menganalisis peluang dan potensi pasar dalam rangka penciptaan dan 
pengambangan usaha bagi tenant. Penelitian pasar dilakukan dalam program PPK untuk menentukan kelayakan dan perilaku pasar dalam konteks supply \& demand yang akan memberikan hasil yang obyektif. Selain itu juga dibimbing cara-cara mencapai pasar secara online (Kienan, 2001). Pembimbingan pasar juga dilakukan dengan mengenalkan para tenant kepada pengembangan usaha secara online melalui pemasaran di media sosisal dan marketplace. Pembinaan pembuatan website akan dilakukan secara intensif sehingga tenant mampu mengelola websitenya untuk meningkatkan pasar secara online.

3. Fase Pelembagaan

Kerjasama antar lembaga

Program ini bertujuan menciptakan jaringan kerjasama antara UMP - Tenant - Lembaga yang prosesnya memanfaatkan keunggulan mitra lembaga, misalnya:

a. untuk meningkatkan produktivitas akan melakukan kerjasama dengan: Dinas Perindustrian dan Perdagangan Kota Pontianak;

b. untuk peningkatan pemasaran akan bekerjasama dengan: UMKM, Dinas Koperasi, PKK, Dekranasda Kota Pontianak, OSS Republik Indonesia Pelayanan Perizinan Berusaha Teritegrasi Secara Elektronik.

Program ini bertujuan mengarahkan dan membimbing proses penyelenggaraan usaha/unit usaha dari suatu organisasi bisnis yang dibentuk, misalnya pembimbingan dalam pembuatan badan hukum (PT, CV, UD), perijinan usaha (SIUP, NPWP, TDP), dan lain-lain.

Kolaborasi dengan lembaga sejenis di luar kampus dan pola operasinya

Kolaborasi dengan lembaga-lembaga diluar kampus dilaksanakan untuk membuat dan mengembangan jaringan usaha dan jaringan pasar. Lembagalembaga dimaksud antara lain:

a. Dinas Koperasi \& UKM, Dinas Perindustrian dan Perdagangan,

b. Dinas Pariwisata \& Ekonomi Kreatif Kota Pontianak.

\section{HASIL DAN PEMBAHASAN}

Luaran Kegiatan Program Pengembangan Kewirausahaan bagi Mahasiswa dan Alumni mengacu pada target yaitu:

1. Terciptanya wirausaha baru mandiri yang berbasis ipteks bagi mahasiswa dan alumni UMP.

2. Meningkatnya keterampilan manajemen usaha dan manajemen keuangan bagi mahasiswa dan alumni UMP.

3. Menciptakan metode pelatihan kewirausahaan yang sesuai bagi mahasiswa yang sedang merintis wirausaha

4. Melaksanakan pendampingan pada mahasiswa yang sudah memulai membuka usaha baru.

Luaran dari program PPK pengembangan kewirausahaan bagi mahasiswa dan alumni tercipta beberapa wirausaha baru dan tenant.

\section{KESIMPULAN}

Program Pengembangan Kewirausahaan yang dilaksanakan bagi mahasiswa dan alumni telah mencapai tujuan yaitu meningkatkan keterampilan manajemen usaha dan manajemen keuangan bagi mahasiswa dan alumni di UMP yang dilakukan melalui pelatihan offline dan online, menciptakan metode pelatihan kewirausahaan yang sesuai bagi mahasiswa yang sedang merintis wirausaha yaitu melalui pelatihan offline dan online pada link: website www.frodine.com, melaksanakan pendampingan pada mahasiswa yang sudah memulai membuka usaha baru, materi kegiatan 
latihan mahasiswa dan alumni telah dirangkum untuk menjadi panduan atau pedoman bagi mahasiswa dan alumni. Hasil program pengembangan kewirausahaan bagi mahasiswa dan alumni akan disebarluaskan dalam bentuk artikel ilmiah.

\section{UCAPAN TERIMA KASIH}

Dengan berhasilnya di tahun ke dua pada program pengabdian hibah Kemenristekdikti RI dengan skema Pengembangan Kewirausahaan, penulis mengucapkan terima kasih kepada Kemenristekdikti RI yang telah mendanai sehingga program ini dapat terlaksana dan Penulis juga mengucapkan terimakasih kepada Lembaga Penelitian dan Pengabdian kepada Masarakat Universitas Muhammadiyah Pontianak, Mitra Tenant Mahasiswa Universitas Muhammadiyah Pontianak atas segala bantuan dan dukungannya dalam pelaksanaan kegiatan Pengabdian kepada masyarakat ini

\section{REFERENSI}

Andiarini, S.E., Arifin, I., Nurabadi, A. 2018. Implementasi Program Penguatan Pendidikan Karakter Melalui Kegiatan Pembiasaan Dalam Peningkatan Mutu Sekolah. Jurnal Administrasi dan Manajemen Pendidikan.

1(2):238-244. http://dx.doi.org/10.17977/um027v1i22018p 238

Awandari, L.P.P., Indrajaya, I.G.B. 2016. Pengaruh Infrastruktur, Investasi, Dan Pertumbuhan Ekonomi Terhadap Kesejahteraan Masyarakat Melalui Kesempatan Kerja. EJurnal Ekonomi Pembangunan. 5(12):1435-1462.

Budiyanto,H., Rofieq, M. 2016. Menumbuhkembangkan Wirausaha Mahasiswa Dan Alumni Melalui Program Iptek Bagi Kewirausahaan Di Universitas Merdeka Malang. Abdimas: Jurnal Pengabdian Masyarakat Universitas Merdeka Malang. 1(1):18-24. https://doi.org/10.26905/abdimas.v1i1.1169

Dongoran F.R., Nisa, K., Sihombing, M., Purba, L.D. 2016. Analisis Jumlah Pengangguran Dan
Ketenagakerjaan Terhadap Keberadaan Usaha Mikro Kecil Dan Menengah Di Kota Medan. EDUTECH: Jurnal Ilmu Pendidikan dan Ilти Sosial. 2(2):59-72. https://doi.org/10.30596/edutech.v2i2.599

Hafni, R. Rozali, A. 2015. Analisis Usaha Mikro, Kecil, Dan Menengah (UMKM) Terhadap Penyerapan Tenaga Kerja Di Indonesia. Ekonomikawan: Jurnal Ilmu Ekonomi dan Studi Pembangunan.

15(2):77-96. https://doi.org/10.30596/ekonomikawan.v1 5i2.1034

Hartina, D. 2009. Faktor-Faktor Yang Mempengaruhi Pengangguran Terselubung Di Perdesaan Jawa Tengah Analisis Data Sakernas 2007. Jurnal Kependudukan Indonesia. 4(1):15-32. https://doi.org/10.14203/jki.v4i1.175

Jaharuddin, J., Purnawan, I., Mujiastuti, R., Muthmainnah, R.N., Prasetyawati, M. 2019. Strategi Melahirkan Mahasiswa Pengusaha Pemula (Studi Kasus Mahasiswa Universitas Muhammadiyah Jakarta). Jurnal Kewirausahaan dan Bisnis. 24(13):25-37. https://doi.org/10.20961/jkb.v24i13.29310

Maryam, E.W., Indriani, R.D.D.S. 2015. Partisipasi Masyarakat Terhadap Upaya Pengentasan Kemiskinan Berbasis Pemberdayaan Perempuan Melalui Program P3EL Kabupaten Sidoarjo. Psikologia: Jurnal Psikologi. 3(1):83-93.

https://doi.org/10.21070/psikologia.v3i1.114

Probosiwi, R. 2016. Unemployment and Its Influence on Poverty Level. Jurnal Penelitian Kesejahteraan Sosial. 15(2):89-100.

Shodikin, A., Sumarno, W.K., Sutardi, S., Muhajir, A. 2018. Program Pengembangan Kewirausahaan Mahasiswa dan Alumni Di Universitas Islam Darul Ulum Lamongan. JPM (Jurnal Pemberdayaan Masyarakat). 3(2):258-263.

https://doi.org/10.21067/jpm.v3i2.2636

Wardhana, A., Kharisma, B., Ibrahim, Y.F. 2019. Pengangguran Usia Muda Di Jawa Barat (Menggunakan Data Sakernas). E-Jurnal Ekonomi dan Bisnis Universitas Udayana. 8(9):1049-1062. https://doi.org/10.24843/EEB.2019.v08.109.p 04 
Wijayanto, H., Ode, S. 2019. Dinamika Permasalahan Ketenagakerjaan Dan Pengangguran Di Indonesia. Administratio: Jurnal Ilmiah Administrasi Publik dan Pembangunan. 10(1):1-8. https://doi.org/10.23960/administratio.v10i 1.82 